\title{
Co-movement of energy prices and stock market return: environmental wavelet nexus of COVID-19 pandemic from the USA, Europe, and China
}

\author{
FengSheng Chien ${ }^{1,2} \cdot$ Muhammad Sadiq $^{3} \cdot$ Hafiz Waqas Kamran ${ }^{4} \cdot$ Muhammad Atif Nawaz $^{5} \cdot$ \\ Muhammed Sajjad Hussain ${ }^{6}$. Muhammad Raza ${ }^{7}$
}

Received: 19 January 2021 / Accepted: 9 February 2021 / Published online: 23 February 2021

(C) The Author(s), under exclusive licence to Springer-Verlag GmbH, DE part of Springer Nature 2021

\begin{abstract}
This work aims to study the time-frequency relationship between the recent COVID-19 pandemic and instabilities in oil price and the stock market, geopolitical risks, and uncertainty in the economic policy in the USA, Europe, and China. The coherence wavelet method and the wavelet-based Granger causality tests are applied to the data (31st December 2019 to 1st August 2020) based on daily COVID-19 observations, oil prices, US-EPU, the US geopolitical risk index, and the US stock price index. The short- and long-term COVID-19 consequences are depicted differently and may initially be viewed as an economic crisis. The results illustrate the reduced industrial productivity, which intensifies with the increase in the pandemic's severeness (i.e., a $10.57 \%$ decrease in the productivity index with a $1 \%$ increase in the pandemic severeness). Similarly, indices for oil demand, stock market, GDP growth, and electricity demand decrease significantly with an increase in the pandemic severeness index (i.e., a $1 \%$ increase in the pandemic severeness results in a $0.9 \%, 0.67 \%, 1.12 \%$, and $0.65 \%$ decrease, respectively). However, the oil market shows low co-movement with the stock exchange, exchange rate, and gold markets. Therefore, investors and the government are recommended to invest in the oil market to generate revenue during the sanctions period.
\end{abstract}

Keywords Wavelet coherence $\cdot$ COVID-19 $\cdot$ Stock market $\cdot$ Oil prices $\cdot$ Global pandemic

\section{Introduction}

Human suffering and loss of life are the primary outcomes of any pandemic. WHO (26th September 2020) (World Health Organization 2020) has already recorded $32,429,965$

Responsible Editor: Nicholas Apergis

Muhammad Sadiq

muhammad.sadiq@taylors.edu.my; sadiq_cima@hotmail.com

FengSheng Chien

jianfengsheng@fzfu.edu.cn

Hafiz Waqas Kamran

hafiz.waqas@iqra.edu.pk

Muhammad Atif Nawaz

atif.nawaz.baloch@gmail.com

Muhammed Sajjad Hussain

sajjadgift@gmail.com

Muhammad Raza

Sirraza81@gmail.com confirmed cases and 985,823 deaths from COVID-19. Such pandemics also cause several multi-dimensional setbacks to the economy and environment. Although the specifics of how much an economy gets affected by COVID-19 are not clear, $30 \%$ of the worldwide residents are under lockdown due to the

1 School of Finance and Accounting, Fuzhou University of International Studies and Trade, Fuzhou, Fujian, China

2 Faculty of Business, City University of Macau, Macau, China

3 School of Accounting and Finance, Faculty of Business and Law, Taylor's University, Subang Jaya, Malaysia

4 Department of Business Administration, Iqra University, Karachi, Pakistan

5 Department of Economics, The Islamia University of Bahawalpur, Bahawalpur, Pakistan

6 The Superior College, Lahore, Pakistan

7 Emaan Institute of Management and Science, Karachi, Pakistan 
severe infection rate. An $\sim 80 \%$ of the global labor force faces closed workplaces and an overall anticipated slump of $0.7 \%$, adding to some of the economic impacts recorded as of now (the worst since the Great Depression) (Sun et al. 2020a, b, c; Samadi et al. 2020). Carbon dioxide $\left(\mathrm{CO}_{2}\right)$ emissions consist of several forms among GHGs that are harmful environmental consequences of human activities (Ikram et al. 2019a, b; Sun et al. 2019). For instance, Ren et al. (2014) discovered that excessive trade surplus coupled with enormous FDI inflows are the main motives for the rapidly rising $\mathrm{CO}_{2}$ emissions in China. Researchers use an estimate for the cost of deaths to measure the financial consequences of pandemics with $\mathrm{CO}_{2}$ emission. For instance, global influenza (the 1918 epidemic) caused a loss recorded at 500-600 billion USD \$/year, measuring up to $0.6 \%$ of the global GDP. This effect is higher for low-middle income countries (1.6\%) as compared with highincome nations (0.3\%) (Mzoughi et al. 2020). According to a joint report by World Health Organization (WHO) and the World Bank, the impact of the present epidemic, however, can cause a loss of 2.2 to $4.8 \%$ in the global GDP (3 trillion USD) (Personal et al. 2016). An (IMF 2020) report points out that the pandemic will severely affect the poor population due to their inability to access enough health care and financial assistance (Tiep et al. 2021).

The sudden drop in oil prices and the major markets' stock prices state the obvious loss from the coronavirus outbreak (Alemzero et al. 2020a, b; Sun et al. 2020a; Gharib et al. 2020). A fall in the stock prices states how the stock prices for the USA, UK, and Italy fell by $32 \%, 27.9 \%$, and $39.3 \%$, respectively. The stock prices for emerging markets face a decline; notably, Brazil, Russia, and China declined by $40.5 \%, 24.2 \%$, and $10.1 \%$, respectively. In contrast, a loss of $\$ 9$ trillion is observed since the outbreak (Sudha et al. 2020). According to some analysts (Jelilov et al. 2020; Haarmeyer 2020), the panic caused out of fear among the investors is the reason for this fall in prices. An expected combination of two factors, combined with the trail of non-OPEC supply growth is expected. This combination is meant to create a balance in the oil price market during the second half of 2020. With an increase in the pandemic, a 30\% sudden loss occurred in oil price, which is the highest fall after the Gulf War of 1991 (Prabheesh et al. 2020; Iqbal et al. 2020).

The stock market is significantly affected by the news around oil prices and the COVID-19 outbreak (Fig. 1). Although oil markets are expected to recuperate which is uncertain to estimate the short- and long-term impacts of the coronavirus outbreak (Yousaf et al. 2020; Tehreem et al. 2020; Wasif Rasheed and Anser 2017; Xu et al. 2020). This uncertainty poses a significant concern for the US policymakers (Corbet et al. 2020, 2021). Esso and Keho (2016) used cointegration bounds testing and Granger causality to investigate the long-term and causal association between energy consumption, $\mathrm{CO}_{2}$ emissions, (Asif et al. 2020; Sarker et al. 2020; Iram et al. 2020; Tehreem et al. 2020), and economic growth. The observational findings are mixed across economies in order to explore the causal relationships regarding energy consumption, carbon dioxide $\left(\mathrm{CO}_{2}\right)$ emissions, and economic growth in (Toda and Yamamoto 1995) Granger causality system. In earlier study, Chuku et al. (2011) used a similar approach and found that trade has no influencing factor $\mathrm{CO}_{2}$ emissions in Nigeria. The concerns under discussion serve as the foundation for this study, making it the first attempt at analyzing the connection and the competition between different players, such as the EU, USA, and China, based on the factors, including the stock market interplay and COVID-19, and oil price. This study uses the wavelet method, focusing on the continuous wavelet transform

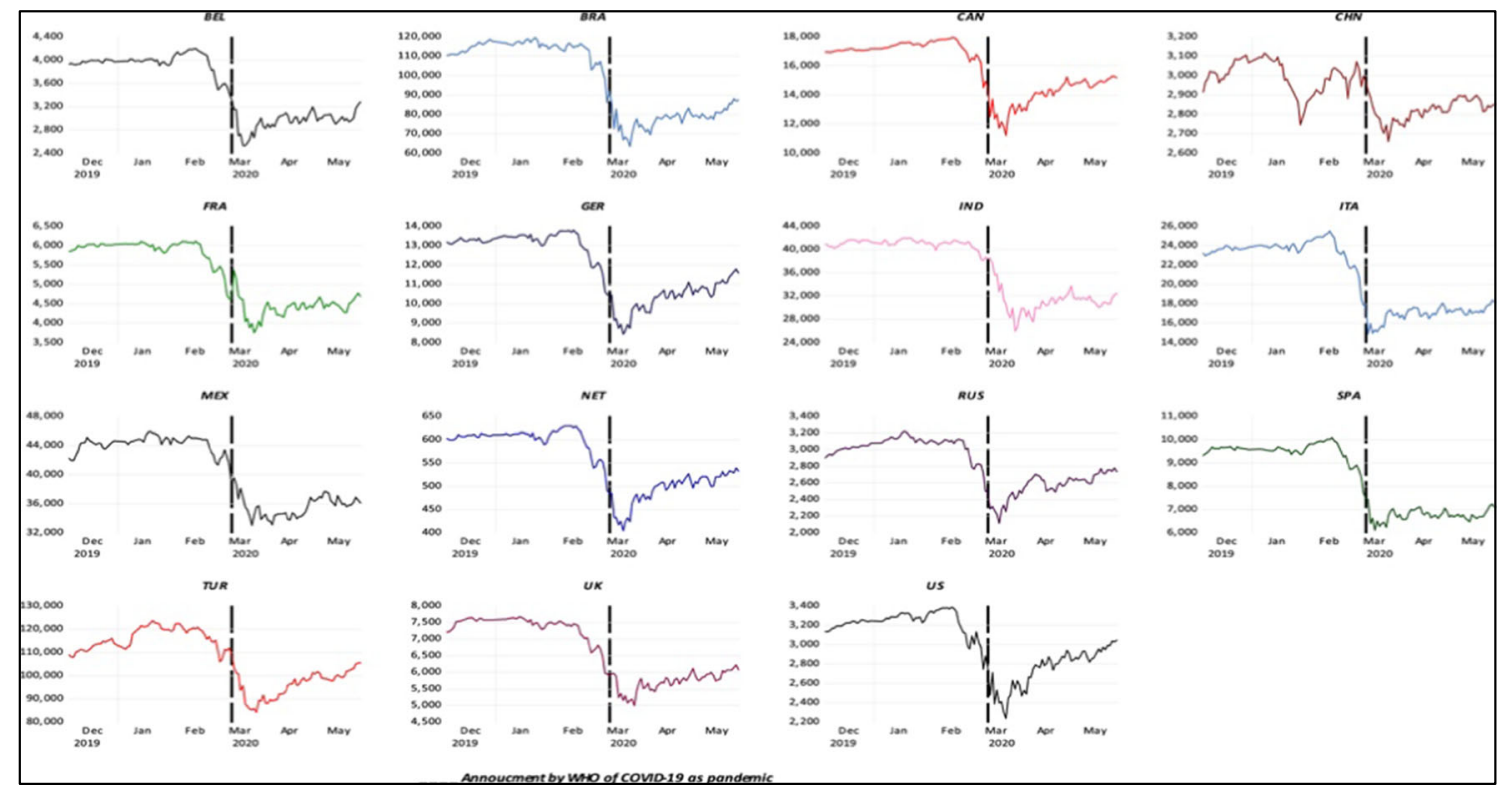

Fig. 1 Global stocks (daily) December 2019-May 2020 
(CWT), wavelet coherence (WC), wavelet spectrum, and the wavelet-based causality tests, implemented on recent data from the USA. A hypothesis is formed based on the given data, explaining the relationship between the news around the COVID-19 pandemic, oil price volatility, and US stock market. The fundamental factor characterizes the time series on its movement. Secondly, the wavelet methods are applied with a nonlinear relationship. Researchers will need data over more extended periods to measure the present and the future time-frequency which is essential to achieve a greater arithmetical implication after the applied tests. Therefore, this study cannot utilize traditional econometric techniques. The current study uses the wavelet method due to no effect of sample size on its results.

This study can prove crucial for policymakers and investors to identify movement in co-moving markets and their direction across various periods. It will also help define if this co-movement will affect a third market. This research can also help study fluctuations caused by a specific market on other markets and the measure to stabilize the affected market.

\section{Data and methodology}

\section{Wavelet approach}

The wavelet model is a potent estimation tool with a single chance to assess co-movements between economic series across the time-frequency dimension through signal processing. It provides significant insights regarding the possible interdependence for different scales. The wavelet analysis extracts information along time and the frequency dimension through time-series spectral bands as a function of time, making it a more effective tool than the other standard methods (Anser et al. 2020e; Khalid Anser et al. 2020). The single occasion truncated in a single frequency range, and the coherent structures across varying scales are differentiated through this method. It employs both locally stationary and nonstationary data, making it a popular economics method due to its flexibility. For a given period, the small "wave packet" in wavelet is seen to go through a rise and fall, whereas the wavelet functions are determined by factors, such as $\psi$ in $L^{2}$ $(R)$. It was documented to be effective with stationary time series (Bilal et al. 2020). According to the indicators of the World Bank (2018), a $\mathrm{CO}_{2}$ emission intensity in Nigeria was 0.59 in 1990 rose to 0.71 in 2014 . Also, the performance of trade has witnessed imbalance growth over the years in Nigeria. Most recently, trade experienced an all-time high (53\% of GDP in 2011) but dropped to $20 \%$ in 2016 due to economic uncertainties. This tells us that industrialization in Nigeria has not been fully utilized because the country is a net importer of goods and services.
It is not suitable to stay restricted to stationary time series when considering complicated. Traditional spectral tools are more likely to miss frequency components that may appear, disappear, and reappear over time. It is possible to overcome the stationarity through wavelet filters as they offer an inherent platform. Events, local in time, are easily captured by the wavelet transform due to its ability to attach itself to capture features across a wide range of occurrences. Therefore, the wavelet transform is the perfect tool to study the nonstationary time series. Factors necessary for the application of Fourier transform include the presence of cyclic time series and the ability of occurrences to not progress with time (for details, see (Lopez-Tiro et al. 2020)). The frame in the wavelet transform keeps varying from low to high and high to low frequency. The analysis of a definite wavelet $\psi($.$) against$ the time sequence $x(t) \in L^{2}(R)$ provides wavelet transforms $W x(m, n)$ shown as:

$W_{x}(m, n)=\int_{-\infty}^{\infty} x(t) \frac{1}{\sqrt{n}} \overline{\psi\left(\frac{t-m}{N}\right)} d t$.

The ability of continuous wavelet transforms to decompose and accordingly recreate as time series $x(t) \in L^{2}(R)$ is one of its essential characteristics, given as:

$x(t)=\frac{1}{C_{\psi}} \int_{0}^{\infty}\left[\int_{-\infty}^{\infty} W_{x}(m, n) \psi_{m, n}(t) d u\right] \frac{d n}{N^{2}}, N>0$

Furthermore, the power of the observed time sequence is preserved by the continuous wavelet transform,

$$
\|x\|^{2}=\frac{1}{C_{\psi}} \int_{0}^{\infty}\left[\int_{-\infty}^{\infty}\left|W_{x}(m, n)\right|^{2} d m\right] \frac{d n}{N^{2}}
$$

The definition of wavelet coherence is stated in this study as quantifying the size and defined framework.

\section{Cross-wavelet transform}

The two sequences for cross wavelet transform $x(t)$ and $y(t)$ are explained as $W X Y=W X W Y *$, where $W X$ and $W Y$ represent the two transforms for wavelets $x$ and $y$, respectively, whereas the composite conjugation is signified by the asterisk sign. With the given time period, the mixed debate (WXY) is considered the original analogous stage between $x n$ and $y n$ (Malhotra and Chintanpalli 2020) as,

$$
D\left(\frac{\left|W_{n}^{X}(s) W_{n}^{Y *}(S)\right|}{\sigma X \sigma Y}<p\right)=\frac{U \vartheta(p)}{\vartheta} \sqrt{P_{k}^{X} P_{k}^{y}}
$$

The assurance level connected with the likelihood $p$ for a likelihood density purpose is $U \vartheta(p)$, described by the square root of the product of two $\chi 2$ distributions. 


\section{Wavelet coherence}

Wavelet coherence is the bivariate structure introduced to analyze the association between two-time series. For an adequate description of wavelet coherence, the cross wavelet transform and cross-wavelet power should be defined first. This twotime sequence $x(t)$ and $y(t)$ can explain the cross wavelet transform as:

$W_{x y}(m, n)=W_{x}(m, n) W_{y}^{*}(m, n)$

where the two continuous wavelet transforms of $x(t)$ and $y(t)$ are given as $W x(m, n)$ and $W y(m, n)$, the location index as $m$, the measure as $n$, and a composite conjugate as the sign *. The cross-wavelet transform given as $|W x(m, n)|$ can easily calculate the cross-wavelet power. A time-frequency gap can be observed by wavelet coherence for a continuously changing time series, which does not necessarily show a massive mutual power (Kisi and Cimen 2011). The equation for the adjusted wavelet coherence coefficient can be seen as follows:

$$
R^{2}(m, n)=\frac{\left|N\left(N^{-1} W_{x y}(m, n)\right)\right|^{2}}{N\left(N^{-1}\left|W_{x}(m, n)\right|^{2}\right) N\left(N^{-1}\left|W_{y}(m, n)\right|^{2}\right)}
$$

$S$ represents the smoothing mechanism, and $0 \leq R^{2}(m, n) \leq$ 1 represents the range of squared wavelet coherence coefficient. Values closer to one imply a more robust correlation, whereas values closer to zero imply a weaker correlation. In this study, the hypothetical allocation for the wavelet coherence cannot be identified, hence using Monte Carlo methods. The method given by Torrence and Compo (1998) and Grinsted et al. (2004) is used in the study for the examination process. Edge situations on data are challenging to manage when using the wavelet approach; Grinsted et al. (2004) defines shaft of control as regions where errors impacted by breaks and gaps in the wavelet transform can be ignored, and the boundary impacts become crucial.

Wavelet coefficients smaller than a threshold are eliminated by hard thresholding. The hard shrinkage function is given by Eq. (3):

$x_{h t}=\left\{\begin{array}{rr}0 i f|x| \leq & \lambda \\ \text { xif }|x|> & \lambda\end{array}\right\}$

Mid thresholding can be adopted as a flexible method, as it provides the mid shrinkage function is given by Eq. (4):

$x_{h t}=\left\{\begin{array}{cc}0 i f|x| \leq & \lambda \\ x-\frac{\lambda 2}{x} i f|x|> & \lambda\end{array}\right\}$

Same like Donoho and Johnstone (1995) in this study, the soft-thresholding method generates better results than mid and hard thresholds in a continuous shrinkage function. The soft shrinkage function is represented as Eq. (5):

$x_{h t}=\left\{\begin{array}{cc}0 i f|x| \leq & \lambda \\ |x|-s \log \left(1+\frac{|x|}{S}\right) i f|x|> & \lambda\end{array}\right\}$

Inspired by Granger and Ramanathan (1984) and Geweke (1992), Breitung and Candelon (2006) used a method for causality analysis in the frequency domain. This method is different from the concept of alternative partial directed coherence (PDC). The Granger causality (GC) frequency domain is explained in detail by the given method, as it classifies the two series based on spectral interdependence. According to Breitung and Candelon (2006), the test presents the relationship reformulation between $x$ and $y$ in the $\operatorname{VAR}(p)$ equation as follows:

$x=a_{1} x_{t-1}+\ldots+a_{p} x_{t-p}+\beta_{1} y_{t-1}+\ldots+\beta_{p} y_{t-p}+\beta_{1 t}$

The null hypothesis was tested by Geweke (1992) for the null linear restriction, given as:

$H_{0}: M y \rightarrow x(\omega)=0$.

\section{Data and variable selection}

Calculated by the Dow Jones 30 index, the data used by this study consists of daily COVID-19 observations, oil prices (WTI), US-EPU (news-based index), the USA-geopolitical risk index (GPR), and the US stock price index (SPI). Centers for Disease Control and Prevention (CDC)'s website is used to gather the data for COVID-19. Similarly, DataStream is the source of data on oil and US stock market, whereas the website of economic policy uncertainty is used for the information on EPU. Caldara and Iacoviello (2018) and Antonakakis et al. (2017) database is used to collect the US-GPR index. Fifty observations for the data collected from 21st January 2020 to 30th March 2020.

\section{Results and discussion}

The uncertainties about the economy and higher concerns for future economic costs as COVID-19 unfolds in the future are the factors making our results valuable. The economic costs will only increase with the spread of COVID-19. Loss of employee productivity, loss of consumer demand, an adverse impact on tourism and other industries, and an impact on foreign direct investment are some of the fundamental factors considered to measure the challenges posed by potential pandemics, both in terms of costs to the health systems and costs of social distancing, before COVID-19. Results show the 
continuous wavelet transforms (CWT) plots for individual variables. Each variable's movements in the time-scales and frequency bands can be analyzed through CWT. In response to Saudi Arabia's least expected price discount announcement and the meltdown in crude oil markets, the risk to the US stock market is evident. $\mathrm{CO} 2$ refers to emission intensity ( $\mathrm{kg}$ per $\mathrm{kg}$ of oil equivalent energy use), I is the gross domestic income, and TI is the trade integration measured by the division of total export and total import of goods and services percentage of GDP. FDI refers to the foreign direct investment net inflows; GDP points to the gross domestic product in growth rate $(\mathrm{K})$ measured by the gross fixed capital formation. This paper used the ARDL bounds testing to cointegration techniques where yearly data from 1980 to 2018 were used. The use of ARDL was called for because we assume linearity to permit us to examine the long-run relationship and possible impact of the explanatory variables on $\mathrm{CO} 2$ emissions that ought to remain the same or uniform.

The EPU index shows a moderately different pattern. The EPU index volatility is high in the starting period due to the increase in the novel infectious disease and China's turbulent sanitary conditions. The EPU for the USA shows the highest value at the end of the sample (around 400 by the end of March 2020), which suggests the unmatched value of EPU in the USA. According to Fig. 2, the CWT plot aligns with the time path of the EPU index. It is easy to spot the two islands with high volatilities for the 1-8 and up to 16-day-frequency bands for the time path of oil price starting in February. The CWT for the visual inspection of the US COVID-19 count shows small islands of high volatility from the beginning of the sample period. The reading coincides with the first wave of deaths in the USA as a result of COVID-19. During the USGPR inspection, the CWT plot is observed to be a mixture free fall of oil prices that are suggested to be responsible for the unexpected rise in an uncertainty. As the US-GPR drops from 559 points to less than 100 points at the beginning of the month, a huge red color island equivalent to considerable instability shocks is identified through the end of February 2020.

Figure 3 shows oil and stock wavelet spectrum. In the scenario of market flooding, the countries of Middle-East can therefore assume payment for sacrificing short-run revenues, while the opportunity cost of these two strategies is reliant on the Middle-East countries' revenue objective function (Anser et al. 2020a, c, f, g, h).

Figure 4 shows the oil and stock prices trend at different time horizon. The arrows are pointed upward and left, which implies the US stock market's leading role in the US-EPU. However, the US market's sudden decrease points to the significant uncertainty about its economic policy. Frequency bands with upward and right arrows, whereas the oil prices continuously fall down due to the decrease in transport and lower expectation of the output growth. The price of oil has a detrimental effect on the socio-economic development of the importing countries as buyers and suppliers of goods and services both struggle.

The vulnerability of the oil i.e., higher costs, contributes to higher vulnerability values. Diversified reserves of oil could result in less risk for disruption. A nation's reliance on oil imports and the risk of oil supply (Anser et al. 2020d) are prone to be more risky in terms of oil supply shortage. A similar amount of oil imported from different oil suppliers is assumed to be facing the very same risk, focusing on four kinds of diversification indexes and the risk of oil supply.

Table 1 shows the oil and stock return. The risk factor with the US dollar is calculated as the amount of the first log discrepancy measured in the volatility of the regular US dollar index. The risk factor of dependence is integrated inside the oil sources to assess risk. Random effect estimator is preferred over the Hausman test due to its insignificantly statistical chisquare. The results show the positive effect on the development of the stock exchange sector of foreign direct investment (FDI). In the long-term tests, their importance is 5\%, while in the short-term outcomes, their importance is $10 \%$. The WPI has an important positive influence on the development of the stock exchange market. The values of both long and short runs are important at $10 \%$. The real prices of oil (ROP) have a significant positive influence on the production of the stock exchange industry. The significant values are at $1 \%$ both long- and short-terms. Nevertheless, the money in circulation has a little effect on the development of the stock exchange industry.

According to Black Monday and Black Tuesday, natural gas companies have the highest stocks, unexpectedly earning between $+17 \%$ and $+11 \%$ daily. It could be due to crude petroleum producers' ability to draw natural gas as a byproduct of the oil extraction process. Due to the oil price decrease in March 2020, crude producers limited natural gas production from the reduced oil output. Six shows an oil-EPU connectedness for different time-scales and frequencies. The recent oil price seriously affects the US economic policy.

Figure 5 shows the COVID-19 index data. US-GPR levels are significantly affected by the massive spread of COVID-19. The wavelet plot is enlightening for dependence between the oil and US-GPR. A considerable measure of dependence can be seen at the initial and end periods of the sample. The 4-8day frequency is covered at the beginning of the sample. The upward left-aligned arrows demonstrate the association of stock market and oil prices. Results present the upward right-aligned arrows, up to 16 days of investment horizons, demonstrating GPR as a fundamental variable.

In particular, we considered the drought response framework of crude oil supply companies, in which the residential sector of the urban crude oil supply industry adjusts the reduction of crude oil supply in a given year. Small-scale and shortduration crude oil supply interruptions show the large amount 
Fig. 2 Oil and stock wavelet coherence

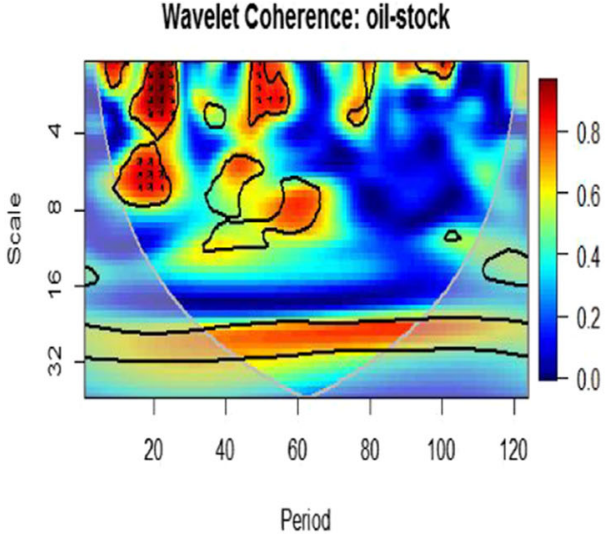

Continuous Wavelet Spectrum:Stock Prices

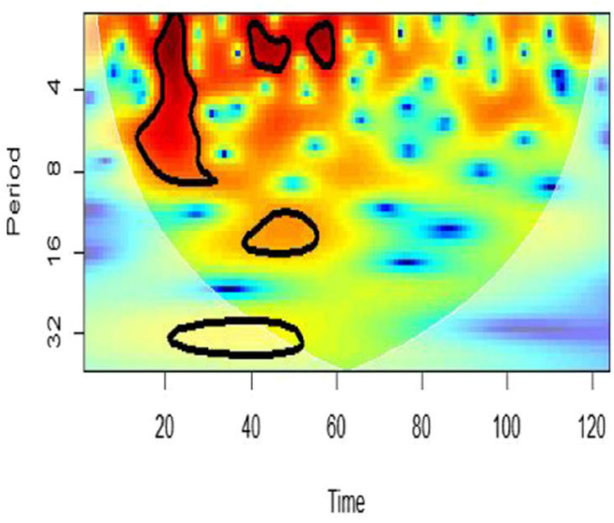

Continuous Wavelet Spectrum:Covid-19 cases

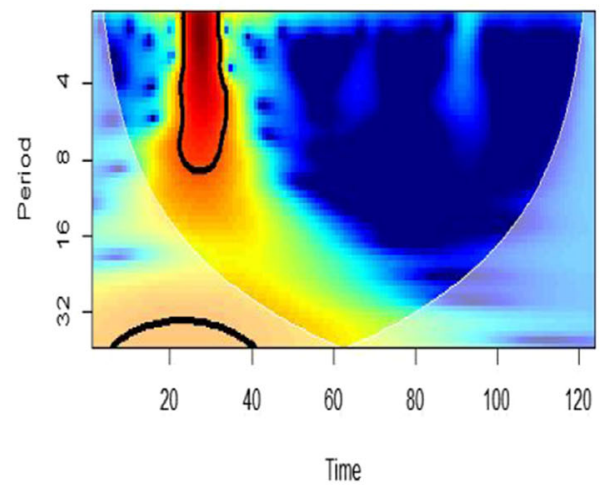

Continuous Wavelet Spectrum:0il Prices

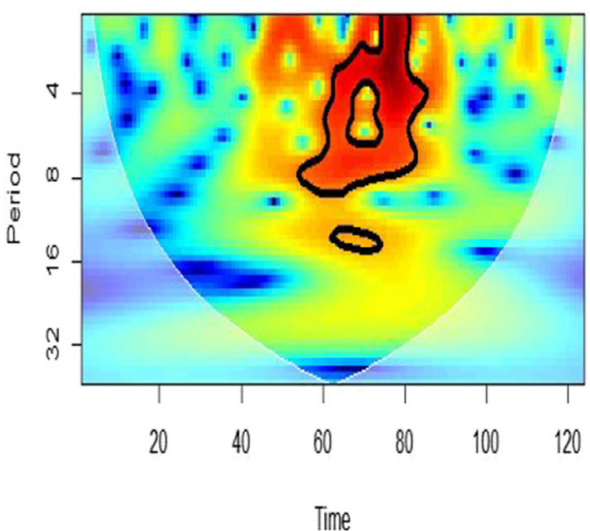

Time

\section{Continuous Wavelet Spectrum:Stock Prices}

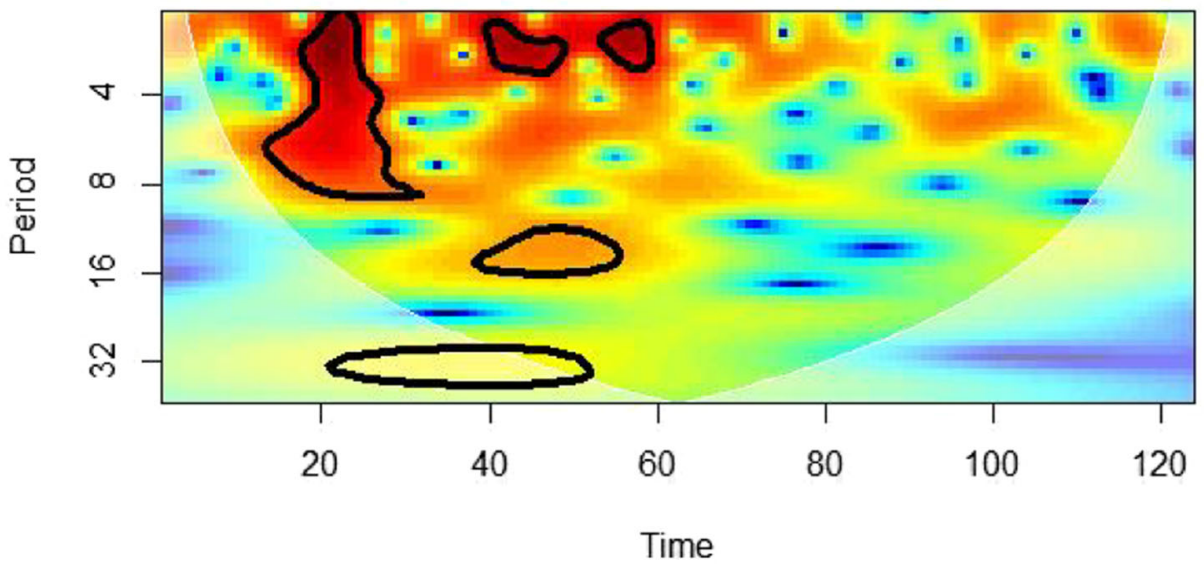

of capital investment required for 1 year and shortened the long-term interruption to short-term. Spatial distribution effects of these three sources of heterogeneity occured in the data. We will also discuss equity considerations based on the IBP schedule. Finally, we estimated and discussed the inefficiency of the distribution of proportional distribution and effective distribution among various utility companies during the regional supply interruption. The environmental impacts of COVID-19 should be addressed to assess the overall effects of the pandemic's socio-economic impacts. Coronavirus causes more than 2.2 billion tons of carbon emission reduction, which makes it the most significant fall recorded in the last century. However, this paper suggests $1.8-2.0$ billion tons reduction in carbon emission. Nevertheless, it is still too early to determine whether this pandemic positively or negatively impacts the climate in the long-run.

Table 2 shows a 0.002 increase in the average comovement of oil prices and exchange rates, which was 
Fig. 3 Oil and stock continous wavelet spectrum
Data1

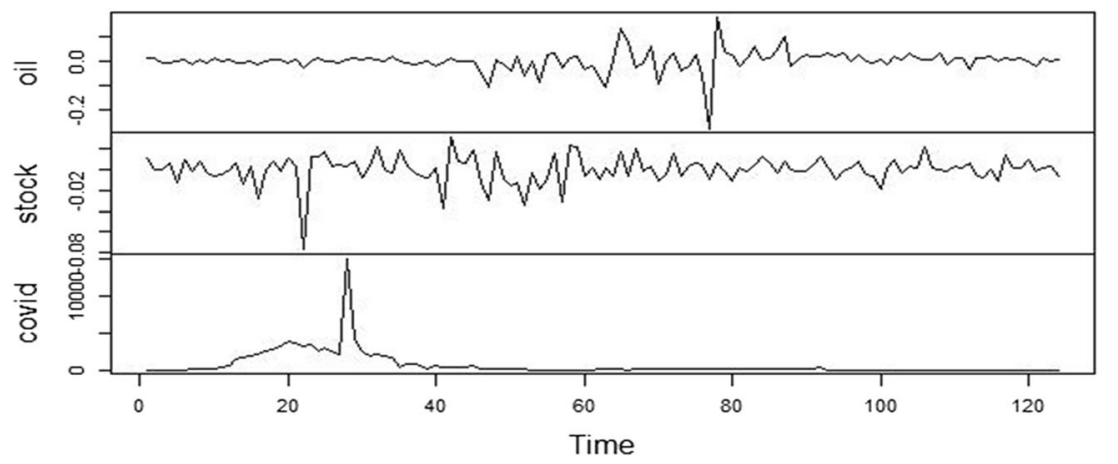

0.18 at the beginning of the period under study (September 2014). However, significant correlation or changes between the two variables are not visible with the sanctions' start (May 2018). At the beginning of the sanctions, the comovement reached -0.17 as it decreased over time. These two variables were considerably affected by the sanctions. The highest value of average co-movement in the pair of variables, gold prices-exchange rates (0.62), was observed at the beginning of the considered period. With time, a continuous decrease was observed until it reached zero for the start of the sanctions. Although the two variables did not observe any significant co-movement, the average co-movement of gold prices and exchange rates observed significant and positive changes during the sanction period. The co-movement of the exchange rates-stock prices pair was recorded at 0.06 at the beginning of the study period and did not vary significantly over time. At the beginning of the sanctions, a 0.2 increase in the average co-movement was observed, decreasing over time. Companies of Middle East are administrated by in the favor of the in the scenario of market flooding; the countries of Middle East can therefore assume payment for sacrificing short-run revenues while the opportunity cost of these two strategies depends on the objective revenue role of the Middle-East countries.

The consideration of extreme cases two polar objective functions wherever they insert all weight autonomous from any political effect at the oil market. They select and design their strategy on the base of reduced collected oil revenues. They also adopt the option of the scenario of market flooding solitary for discount rates lesser than $7 \%$.

The size, activity, and efficiency of financial intermediaries and the stock market's activity and efficiency are directly related to COVID-19, oil, stock exchange, and gold. During the COVID-19 outbreak, the logarithm of trade openness is included in the control variable set. The standard errors indicate $1 \%, 5 \%$, and $10 \%$ significance are included in parentheses, which are ***, **, and *, respectively. The inverted U-shaped relationship between financial structural activity and economic growth is shown in the first column of Table 3. Statistically positive and negative values for the linear and quadratic terms of financial structure activity can precisely be found here. The marginal effect of financial structural activity seems to turn negative when it reaches up to $168 \%$, as shown in the regression point estimate (Mohsin et al. 2020). COVID-19 is widely concerned with social actors, policymakers, and society as a whole. The literature indicates that the COVID-19 outbreak has wide influences on oil prices and stock market performance. Studies highlighted through the wavelet analysis technique that the COVID-19 outbreak is significantly impacting stock market volatility. More so, COVID-19 is causing negative national economic growth and rising uncertainty in the markets and negatively affecting the oil prices. These results are proved by using a lead-lag relationship and linear relationships. The associations between COVID-19, oil prices, and stock market return variables vary across time-scales and investment horizons, where both cyclical and anti-cyclical patterns of connectedness have been identified. The outcome of the relationship between carbon $\left(\mathrm{CO}_{2}\right)$ emissions and fixed capital is consistent with that reported in Mohsin et al. (2018b, 2019, 2020). The authors found that increased fixed capital has reduced carbon $\left(\mathrm{CO}_{2}\right)$ emissions and enhanced environmental efficiency.

\section{Robustness analysis}

As mentioned in earlier studies, the US market's considerable sensitivity to oil volatility shocks stated their alignment with the results given above. The effect of D1 and D2 does not cause the US-GPR risk levels over all the selected frequency bands. This result may occur as US investors consider the COVID-19 eruption primarily as a financial catastrophe instead of a reverse geopolitical event. Considering the two exogenous shocks as being independent, the oil price volatility over the remaining frequency domains is unaffected by the effects of COVID- 19 .

It is not feasible to produce and refine $10 \%$ of the global oil from the fall in the oil price to the pretwenty-first-century mark Mohsin et al. (2018a, 2019). Therefore, it is up to the oil-producing countries to control the energy market, which helps their consumers from facing worse economic circumstances. 

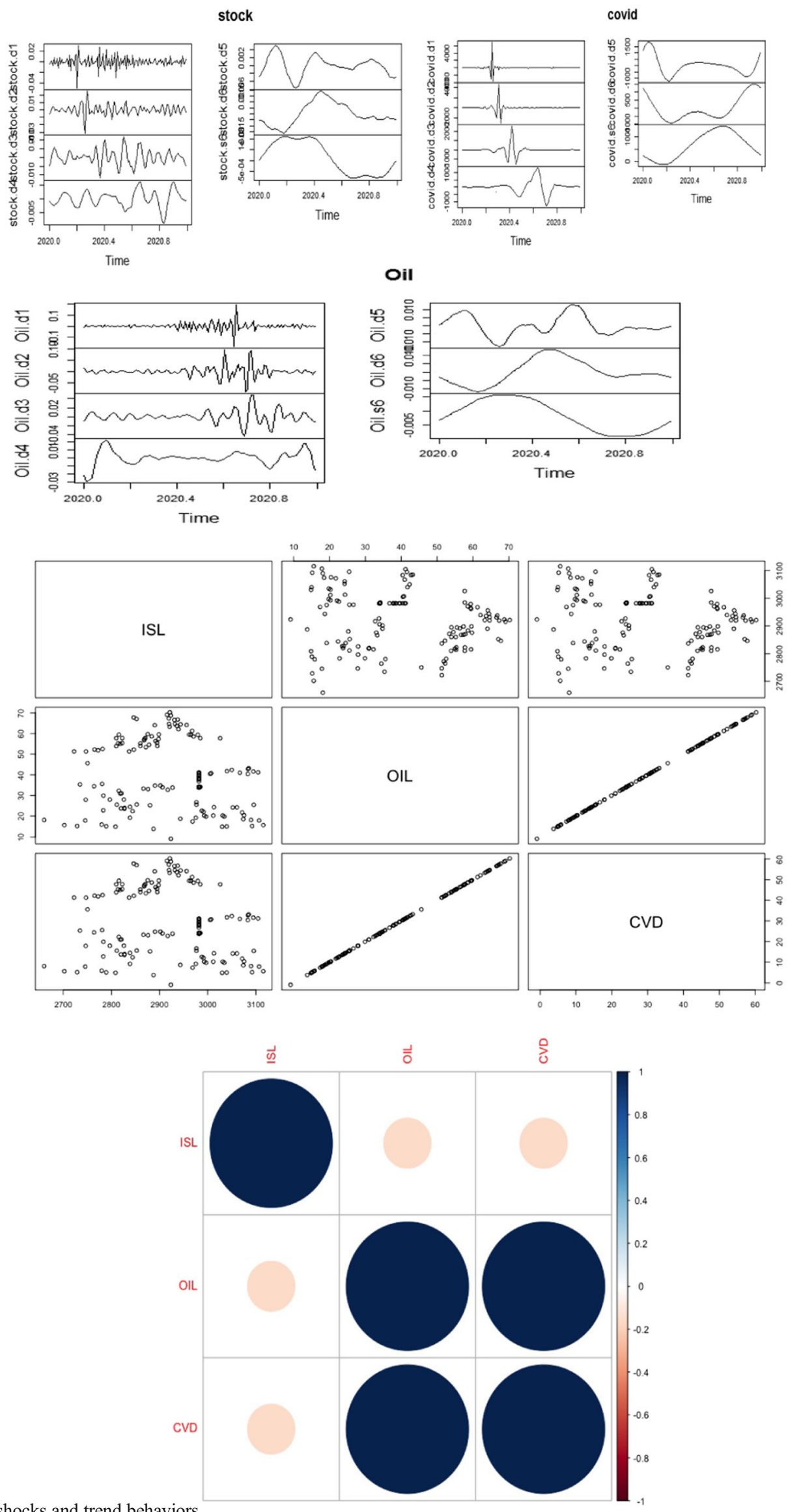

Fig. 4 Oil and stock shocks and trend behaviors 
Table 1 Oil and stock return

\begin{tabular}{llllllllll}
\hline S\&P & NSDAQ & DOW & DAX & CRIA & Shanghai & $\begin{array}{l}\text { Cyprus } \\
\text { SE }\end{array}$ & CROBEX & $\begin{array}{l}\text { Oil } \\
\text { prices }\end{array}$ & $\begin{array}{l}\text { Oil } \\
\text { return }\end{array}$ \\
\hline 0.01 & 0.01 & 0.00 & 0.00 & 0.00 & 0.01 & 0.00 & 0.00 & $34.15 \$$ & 0.01 \\
0.02 & 0.00 & -0.01 & 0.01 & -0.04 & 0.01 & 0.00 & 0.01 & $33.98 \$$ & -0.01 \\
0.01 & 0.01 & 0.02 & 0.01 & 0.00 & -0.01 & 0.00 & 0.00 & $32.73 \$$ & 0.02 \\
-0.02 & 0.00 & 0.02 & -0.01 & 0.00 & 0.00 & 0.00 & 0.00 & $33.95 \$$ & -0.06 \\
0.01 & 0.00 & 0.00 & 0.01 & 0.00 & 0.00 & 0.00 & -0.01 & $33.80 \$$ & -0.01 \\
-0.03 & -0.01 & 0.00 & -0.03 & -0.01 & 0.00 & 0.01 & -0.01 & $34.78 \$$ & 0.02 \\
0.00 & 0.02 & 0.02 & 0.02 & 0.00 & 0.01 & -0.01 & 0.00 & $34.76 \$$ & 0.01 \\
0.01 & -0.01 & -0.02 & -0.01 & -0.05 & 0.00 & 0.00 & 0.00 & $33.06 \$$ & 0.03 \\
-0.01 & 0.02 & 0.04 & 0.00 & 0.00 & 0.00 & 0.01 & 0.00 & $33.30 \$$ & -0.01 \\
0.00 & 0.01 & 0.00 & -0.01 & 0.00 & 0.01 & 0.00 & 0.00 & $30.95 \$$ & 0.03 \\
0.00 & 0.01 & 0.02 & 0.01 & 0.00 & -0.01 & 0.00 & 0.00 & $29.87 \$$ & 0.02 \\
0.02 & -0.02 & -0.02 & 0.03 & 0.07 & 0.00 & 0.00 & 0.00 & $27.89 \$$ & 0.02 \\
0.01 & -0.02 & -0.02 & 0.00 & 0.03 & -0.01 & 0.00 & 0.00 & $26.67 \$$ & -0.09 \\
0.01 & 0.01 & 0.00 & 0.00 & 0.00 & 0.00 & 0.01 & 0.00 & $25.53 \$$ & 0.02 \\
-0.06 & 0.02 & 0.02 & -0.04 & 0.00 & 0.01 & -0.01 & 0.00 & $24.23 \$$ & 0.02 \\
-0.01 & 0.01 & 0.01 & -0.01 & -0.01 & 0.00 & 0.01 & 0.00 & $24.20 \$$ & -0.03 \\
-0.01 & 0.01 & -0.01 & -0.02 & -0.04 & 0.00 & 0.00 & 0.00 & $25.46 \$$ & 0.06 \\
0.01 & 0.01 & 0.01 & 0.00 & -0.16 & 0.00 & 0.01 & 0.00 & $20.40 \$$ & 0.01 \\
0.03 & 0.01 & 0.00 & 0.03 & -0.01 & 0.00 & 0.00 & 0.00 & $18.49 \$$ & 0.01 \\
0.00 & -0.03 & -0.03 & 0.00 & -0.02 & 0.00 & 0.00 & 0.00 & $18.11 \$$ & 0.03 \\
0.01 & 0.00 & -0.01 & 0.04 & 0.00 & 0.02 & 0.01 & 0.01 & $17.86 \$$ & 0.07 \\
\hline & & & & & & & & & \\
\end{tabular}

Table 4 shows the sensitivity analysis based on Granger causality. The causality is strongly influencing the oil price for all the selected frequencies for EPU. It is suggested that the uncertainty in the US economic conditions is the main cause of an increase of the GPR levels. Recent studies have indicated novel changes in sustainable products like cleaning and sanitizing the workplace, implementing social distance, minimizing travel, and reducing transportation. However, novel changes about the supply chains, social innovations, and technology have been observed due to the coronavirus outbreak (Sarkis et al. 2020). The production and supply system are interrupted from the outbreak of the COVID-19, and strategies

Fig. 5 COVID-19 index data

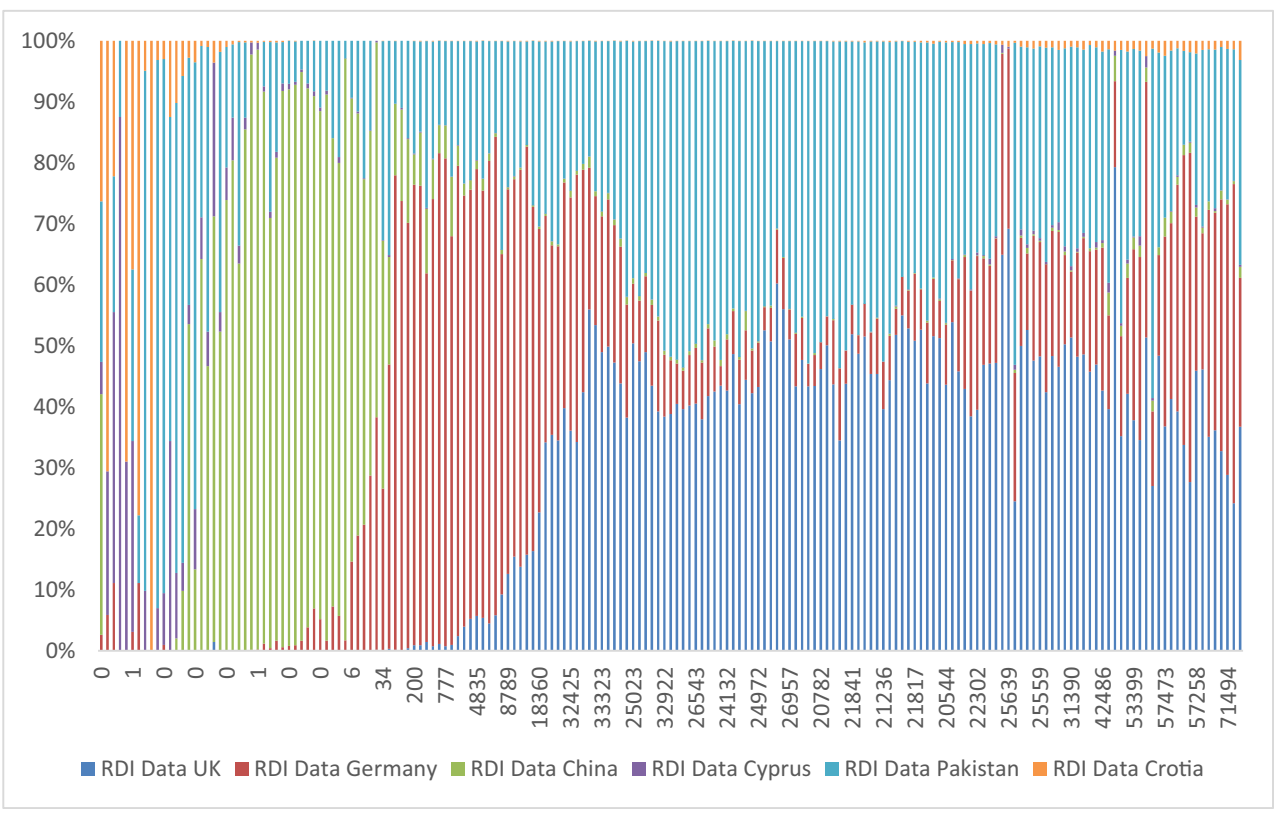


Table 2 Econometric estimation

\begin{tabular}{|c|c|c|c|c|c|c|c|}
\hline Dependent variable $\rightarrow$ Coefficient & $\mathrm{t} \quad \beta_{0}$ & $\beta_{1}$ & $\beta_{2}$ & $\beta_{3}$ & $\beta_{4}$ & $\beta_{5}$ & $F$-static \\
\hline Exchange rate and stock price & $0.06(0.00)$ & $0.004(0.10)$ & $0.19(0.00)$ & $-0.006(0.04)$ & $0.20(0.80)$ & $-0.003(0.92)$ & $13.45(0.00)$ \\
\hline Gold price and exchange rate & $0.59(0.00)$ & $-0.005(0.00)$ & $-0.041(0.33)$ & $0.004(0.02)$ & $0.51(0.74)$ & $-0.007(0.76)$ & $17.53(0.00)$ \\
\hline Gold price and stock price & $0.15(0.00)$ & $0.0008(0.53)$ & $0.21(0.01)$ & $-0.002(0.16)$ & $1.02(0.29)$ & $-0.009(0.3)$ & $12.43(0.00)$ \\
\hline Oil price and gold price & $0.14(0.00)$ & $-0.002(0.00)$ & $-0.12(0.00)$ & $0.007(0.00)$ & $0.30(0.70)$ & $0.008(0.50)$ & $29.32(0.00)$ \\
\hline Oil price and stock price & $0.07(0.00)$ & $0.003(0.00)$ & $0.11(0.21)$ & $-0.002(0.09)$ & $0.37(0.69)$ & $-0.008(0.66)$ & $6.76(0.00)$ \\
\hline Oil price and exchange rate & $0.21(0.00)$ & $0.002(0.00)$ & $-0.01(0.17)$ & $-0.001(0.80)$ & $-0.29(0.73)$ & $0.005(0.34)$ & $18.34(0.00)$ \\
\hline
\end{tabular}

and policies are set to design new patterns and deal with the demand of consumers for production. It is vivid that raw products and raw materials were supplied from China and Asian countries worldwide. Still, the pandemic situation gave a break to the transportation, and supply was shortened. Thus, priorities were given to the demand for basic and mandatory products and services. Therefore, policy strategies are set to improve the system's resilience and sustainability (Khalid Anser et al. 2020; Mohsin et al. 2021; Yang et al. 2021). The economic and market fluctuations have contributed to the sustainability transition and enabled us to remain proactive to respond to the challenges. Besides the consumption of mass products, integration of social, economic, environmental, and institutional opportunities offer opportunities. Government restrictions and volunteer social distancing created room for the investigation filled with this study (Anser et al. 2020b; He et al. 2020).

\section{Environmental consideration regarding COVID-19}

The ongoing situation of the COVID-19 pandemic illustrated remarkable effects on the global economy where green finance enabled significant measures to sustain the economy's environment. Various proactive approaches used in global to establish dominant alliances to support the economy, but macroeconomic factors also stated significant influence among them. COVID-19 established all possible effects over the economic growth with green finance dominance, which helped global to pose a sustainable environment for economic growth. The serious contradiction also eminently discussed in the environment of economic growth and green finance's resilience established positive measures though. Plenty of challenges effectively prevailed in global economies, but the effectiveness of green finance inserted possible influences with covering measures to safe economic growth.

Table 3 Effects of financial structure on economic growth

\begin{tabular}{|c|c|c|c|c|c|c|}
\hline & $(1)$ & $(2)$ & (3) & (4) & $(5)$ & $(6)$ \\
\hline & \multicolumn{3}{|c|}{ Boldrin and Levine (2002) } & \multicolumn{3}{|c|}{ Cuadro-Sáez and García-Herrero (2007) } \\
\hline \multirow[t]{2}{*}{ COVID-19 } & 0.188 & & & 0.454 & & \\
\hline & $(0.253)$ & & & $(0.599)$ & & \\
\hline \multirow[t]{2}{*}{ Oil } & & $0.729 * * *$ & & & $1.711 * * *$ & \\
\hline & & $(0.221)$ & & & $(0.512)$ & \\
\hline \multirow[t]{2}{*}{ Stock } & & & $0.421 * *$ & & & $1.06^{* *}$ \\
\hline & & & $(0.137)$ & & & $(0.473)$ \\
\hline \multirow[t]{2}{*}{ Lag of dependent variable } & $0.199 * *$ & $0.152 * * *$ & 0.053 & $0.162 * *$ & $0.176^{* * *}$ & 0.067 \\
\hline & $(0.061)$ & $(0.053)$ & $(0.051)$ & $(0.053)$ & $(0.061)$ & $(0.049)$ \\
\hline \multirow[t]{2}{*}{ Gold } & $-0.782 * * *$ & $-0.822 * * *$ & $-1.013 * * *$ & $-0.921 * * *$ & $-0.888 * * *$ & $-1.041 * * *$ \\
\hline & $(0.197)$ & $(0.194)$ & $(0.305)$ & $(0.222)$ & $(0.259)$ & $(0.323)$ \\
\hline \multirow[t]{2}{*}{ Trade openness } & $1.748 * * *$ & $1.865 * * *$ & $0.712 *$ & $1.399 * * *$ & $1.582 * * *$ & $0.702 *$ \\
\hline & $(0.496)$ & $(0.403)$ & $(0.426)$ & $(0.486)$ & $(0.375)$ & $(0.466)$ \\
\hline \multirow[t]{2}{*}{ Constant } & 4.433 & 4.490 & $6.605 * *$ & 4.622 & $5.522 *$ & $7.717 * *$ \\
\hline & $(2.775)$ & $(2.645)$ & $(3.173)$ & $(3.062)$ & $(2.568)$ & $(3.202)$ \\
\hline $\mathrm{AR}(2) p$-value & 0.782 & 0.885 & 0.642 & 0.920 & 0.966 & 0.192 \\
\hline Hansen $p$-value & 0.442 & 0.546 & 0.997 & 0.534 & 0.783 & 0.995 \\
\hline
\end{tabular}

This table reports the estimation results of model (1). The dependent variable is real GDP

* Shows $10 \%$ significance level, ** shows $5 \%$ significance level, *** Shows $1 \%$ significance level 
Table 4 Sensitivity analysis wavelet-based Granger causality

\begin{tabular}{|c|c|c|c|c|c|}
\hline \multirow[t]{2}{*}{ Frequency domains } & \multirow[t]{2}{*}{ Dependent variables } & \multicolumn{4}{|c|}{ Independent variables } \\
\hline & & Stock & $\begin{array}{l}\text { COVID- } \\
19\end{array}$ & Gold & Oil \\
\hline \multirow[t]{4}{*}{ D1 } & Stock & & 0.813 & $17.382 * * *$ & \\
\hline & COVID-19 & $7.613 *$ & - & $19.583 * * *$ & 1.584 \\
\hline & Gold & $61.844 * * *$ & 1.548 & - & $22.491 * * *$ \\
\hline & Oil & $30.324 * * *$ & 2.984 & $09.524 * *$ & - \\
\hline \multirow[t]{4}{*}{ D2 } & Stock & & 0.813 & $17.382 * * *$ & \\
\hline & COVID-19 & $7.984 *$ & - & $18.783 * * *$ & 1.876 \\
\hline & Gold & $62.564 * * *$ & 1.763 & - & $21.723 * * *$ \\
\hline & Oil & $31.785 * * *$ & 2.862 & $10.621 * *$ & - \\
\hline \multirow[t]{4}{*}{ D3 } & Stock & & 0.813 & $17.382 * * *$ & \\
\hline & COVID-19 & $6.632 *$ & - & $17.743 * * *$ & 1.654 \\
\hline & Gold & $61.634 * * *$ & 1.895 & - & $20.8643 * * *$ \\
\hline & Oil & $32.785 * * *$ & 2.657 & $10.787 * *$ & - \\
\hline \multirow[t]{4}{*}{ D4 } & Stock & & 0.986 & $18.657 * * *$ & \\
\hline & COVID-19 & $7.002 *$ & - & $18.863 * * *$ & 1.786 \\
\hline & Gold & $62.434 * * *$ & 1.764 & - & $21.864 * * *$ \\
\hline & Oil & $32.785 * * *$ & 2.657 & $10.787 * *$ & - \\
\hline \multirow[t]{4}{*}{ D5 } & Stock & & 0.813 & $17.382 * * *$ & \\
\hline & COVID-19 & $6.632 *$ & - & $17.743 * * *$ & 1.654 \\
\hline & Gold & $61.634 * * *$ & 1.895 & - & $20.8643 * * *$ \\
\hline & Oil & $32.785 * * *$ & 2.657 & $10.787 * *$ & - \\
\hline \multirow[t]{4}{*}{ D6 } & Stock & & 0.986 & $18.657 * * *$ & \\
\hline & COVID-19 & $7.002 *$ & - & $18.863 * * *$ & 1.786 \\
\hline & Gold & $62.434 * * *$ & 1.764 & - & $21.864 * * *$ \\
\hline & Oil & $32.785 * * *$ & 2.657 & $10.787 * *$ & - \\
\hline \multirow[t]{4}{*}{ Original } & Stock & & 0.986 & $18.657 * * *$ & \\
\hline & COVID-19 & $7.002 *$ & - & $18.863 * * *$ & 1.786 \\
\hline & Gold & $62.434 * * *$ & 1.764 & - & $21.864 * * *$ \\
\hline & Oil & $32.785 * * *$ & 2.657 & $10.787 * *$ & - \\
\hline
\end{tabular}

* Shows $10 \%$ significance level, ** shows $5 \%$ significance level, *** Shows $1 \%$ significance level
The element of environmental concern is included in the other areas in the maintenance of the status of inclusive economic development, and it proves its significance with the statistics from the population of the region. The energy sector plays a backbone role in the economy of any country. Over time, this sector is getting more and more important. Green credit initiatives are important to make the economy stable and well-established. Eco-friendly biofuels and recyclable material usage are essential for the growth of the economy. Green credit investment options are beneficial for Pakistan's prosperity. Green securities are safe investment options for the well-being of green economic growth and development. The use of environmentally friendly materials in business firms for manufacturing purposes is imperative for the community's well-being. Developed countries like China have implemented safe financing approaches for the well-being of their economy. The companies have proper strategies to support the health insurance and other health-related implications. Environmental sustainability options are essential to support prosperity and economic growth.

\section{Discussion}

A global-scale decrease in environmental pollution was observed due to a significant decrease in energy demand during the lockdown period. 2020 is likely to face the biggest fall in global energy demand which is expected to be around 5\%. As compared with the same period in 2019, the end of April is said to experience a $17 \%$ decrease in worldwide emissions (Kannan et al. 2020), and global lockdown is considered the fundamental drivers for measuring the extent of emission 
reduction effect of COVID-19, suggesting a potential reduction of 7\%. Index-only investments during 2019-2020 can directly be compared with the downside for portfolios containing ethereum and tether. The only evidence for a reduction in downside risk of ethereum is due to CSI 300 . A significant increase is found with an MVaR of $11.47 \%$ at a $1 \%$ confidence level for FTSE 100, but when combined with $10 \%$ ethereum, it increases by $28.9 \%$ with the remaining $90 \%$ allocated to the FTSE 100 . Over this period, tether provides safe-haven characteristics. A reduction in the downside risk is observed with Tether's allocation for each of the equity indices.

However, the safe-haven properties of Tether cannot be confirmed through this data. If a firm freezes between Tethers, a $10 \%$ decrease in downside risk should occur from a $10 \%$ allocation, which is equivalent to $10 \%$ of the unallocated portfolio in the presence of the US dollar. Considering a range of different allocation weights, we test this concept and the proportional reduction in downside risk across all the assets. However, this is novel evidence, confirming empirically that they have impacted the stock returns themselves, once changes in conditional volatility are considered. Several events and activities are disrupted globally due to the pandemic COVID-19 and have dragged all the transformations occurring in the production of the goods and their supply. This has designed new actions and courses to go through the process of stock market business. Resultantly, transition in sustainability has become mandatory (Mohsin et al. 2020). COVID-19 signals for the change in new behavior for the suitable actions for the business managers and policymakers concerned with the sustainable production and supply and the transition in the prospects of sustainability (Sun et al. 2020b).

\section{Conclusion and policy implication}

This work examined the time-frequency relationship between the recent COVID-19 pandemic and instabilities in oil price and the stock market, geopolitical risks, and uncertainty in the economic policy in the USA, Europe, and China. The coherence wavelet method and the wavelet-based Granger causality tests are applied to the data (from 31st December 2019 to 1st August 2020) based on daily COVID-19 observations, oil prices, US-EPU, the US-geopolitical risk index, and the US stock price index. The findings show a dramatic fall in oil and stock prices with an increase in the severity of COVID-19, which is found to be significantly strong post-5th April 2020. The March 2020 COVID-19 stock crash was one of the largest stock market crashes in history, where the market had a $26 \%$ fall in four days. The US GDP of the first quarter of 2020 was down $4.8 \%$, while the unemployment rate was over $20 \%$.

Analysis from the wavelet-based approach helps overcome practical challenges (such as stationarity and non-linearity) by analyzing time-frequency lead-lag interactions. Results from the segmented regression analysis illustrate the significance of the re-imposition of sanctions between gold prices and exchange rates. Consequently, short-, medium-, or long-term investments in either gold or foreign exchange are risks for investors during the COVID-19 pandemic. This finding is essential for policy-makers and government officials, who can control the foreign exchange market to stabilize the gold market in crisis times. The oil market shows low comovement with the stock exchange, exchange rate, and gold markets. Therefore, investors and the government are recommended to invest in the oil market to generate revenue during the sanctions period. This study contributes to the vast pool of literature on COVID-19 and its financial implications, particularly focusing on Bitcoin as a potential investment in this pandemic situation.

These results about the introduction of environmental aspects into the financial policies like a green investment and securities, and thereby the movement in the establishment and development of the renewable energy enterprises in an economy where the pandemic COVID-19 prevails.

\section{Policy implication}

Green investment initiatives are the credit options that have future implications for the development and prosperity of the economy of a country. In developing countries, insurance-based options are scarce, but efforts are in progress for the economic sector's well-being. Business communities throughout the world have focused on the development of green insurance-based options. The companies are providing green investment platforms that support the overall green credit loans. Companies all over the world have a transparent set of social and economic development initiatives that supplement the overall green economy and green investments. These initiatives support the eco-friendly approaches and show the extent of social responsibility in the industries. The new and innovative production units generate no harmful effluents and waste materials. These plants are not only cost-effective but also supportive of the growth and development of economic growth initiatives. Biomass and agricultural wastes are abundant in developing countries. Developing economies can use all these wastes for the generation of bio-friendly fuels. These fuels can easily produce new and innovative products. These products can easily support the infrastructure of the country. Industrial units that have adopted eco-friendly ways of production have more production rate than the traditional industrial units. The need is to enhance the number of such eco-friendly and economically sound industrial units.

Author contribution FengSheng Chien: conceptualization, data curation, methodology, writing — original draft. Muhammad Sadiq: data curation, visualization. Hafiz Waqas Kamran: visualization, supervision, editing. Muhammad Atif Nawaz: review and editing. Muhammed Sajjad 
Hussain: writing - review and editing and software. Muhammad Raza: editing, reviewing.

Data availability The data that support the findings of this study are openly available on request.

\section{Declarations}

\section{Ethical approval and consent to participate N/A}

Consent for publication We do not have any individual person's data in any form.

Competing interest The authors declare that they have no conflict of interest.

\section{References}

Alemzero DA, Iqbal N, Iqbal S et al (2020a) Assessing the perceived impact of exploration and production of hydrocarbons on households perspective of environmental regulation in Ghana. Environ Sci Pollut Res. https://doi.org/10.1007/s11356-020-10880-3

Alemzero DA, Sun H, Mohsin M, Iqbal N, Nadeem M, Vo XV (2020b) Assessing energy security in Africa based on multi-dimensional approach of principal composite analysis. Environ Sci Pollut Res 28:2158-2171. https://doi.org/10.1007/s11356-020-10554-0

Anser MK, Alharthi M, Aziz B, Wasim S (2020a) Impact of urbanization, economic growth, and population size on residential carbon emissions in the SAARC countries. Clean Techn Environ Policy 22:923936. https://doi.org/10.1007/s10098-020-01833-y

Anser MK, Ali M, Anwar F, Usman M (2020b) Subjective age and job satisfaction: a moderated mediation model of job burnout and chronological age. Front Public Health 8. https://doi.org/10.3389/fpubh. 2020.00062

Anser MK, Hanif I, Alharthi M, Chaudhry IS (2020c) Impact of fossil fuels, renewable energy consumption and industrial growth on carbon emissions in Latin American and Caribbean economies. Atmosfera. https://doi.org/10.20937/ATM.52732

Anser MK, Khan MA, Awan U, Batool R, Zaman K, Imran M, Sasmoko, Indrianti Y, Khan A, Bakar ZA (2020d) The role of technological innovation in a dynamic model of the environmental supply chain curve: evidence from a panel of 102 countries. Processes 8 . https:// doi.org/10.3390/pr8091033

Anser MK, Yousaf Z, Nassani AA, Abro MMQ, Zaman K (2020e) The role of carbon pricing in the relationship between air freight and environmental resource depletion: a case study of Saudi Arabia. Clean Techn Environ Policy. https://doi.org/10.1007/s10098-02001844-9

Anser MK, Yousaf Z, Nassani AA, Abro MMQ, Zaman K (2020f) International tourism, social distribution, and environmental Kuznets curve: evidence from a panel of G-7 countries. Environ Sci Pollut Res 27:2707-2720. https://doi.org/10.1007/s11356-01907196-2

Anser MK, Yousaf Z, Usman B, Nassani AA, Qazi Abro MM, Zaman K $(2020 \mathrm{~g})$ Management of water, energy, and food resources: go for green policies. J Clean Prod 251:119662. https://doi.org/10.1016/j. jclepro.2019.119662

Anser MK, Yousaf Z, Zaman K, Nassani AA, Alotaibi SM, Jambari H, Khan A, Kabbani A (2020h) Determination of resource curse hypothesis in mediation of financial development and clean energy sources: go-for-green resource policies. Res Policy 66:101640. https://doi.org/10.1016/j.resourpol.2020.101640
Antonakakis N, Gupta R, Kollias C, Papadamou S (2017) Geopolitical risks and the oil-stock nexus over 1899-2016. Financ Res Lett 23: 165-173. https://doi.org/10.1016/j.frl.2017.07.017

Asif M, Khan KB, Anser MK, Nassani AA, Abro MMQ, Zaman K (2020) Dynamic interaction between financial development and natural resources: evaluating the 'resource curse' hypothesis. Res Policy 65:101566. https://doi.org/10.1016/j.resourpol.2019.101566

Bilal BMF, Benghoul M et al (2020) Environmental pollution and COVID-19 outbreak: insights from Germany. Air Qual Atmos Health 13:1385-1394. https://doi.org/10.1007/s11869-020-00893-9

Boldrin M, Levine D (2002) The case against intellectual property. Am Econ Rev 92(2):209-212

Breitung J, Candelon B (2006) Testing for short- and long-run causality: a frequency-domain approach. J Econ 132:363-378. https://doi.org/ 10.1016/j.jeconom.2005.02.004

Caldara D, Iacoviello M (2018) Measuring geopolitical risk. Int Financ Discuss Pap. https://doi.org/10.17016/ifdp.2018.1222

Chuku CA, Akpan UF, Sam NR, Effiong EL (2011) Oil price shocks and the dynamics of current account balances in Nigeria. OPEC Energy Rev 35:119-139. https://doi.org/10.1111/j.1753-0237.2011.00186. $\mathrm{x}$

Corbet S, Hou Y, Hu Y, Oxley L (2020) The influence of the COVID-19 pandemic on asset-price discovery: testing the case of Chinese informational asymmetry. Int Rev Financ Anal 72:101560. https://doi. org/10.1016/j.irfa.2020.101560

Corbet S, Hou Y(G), Hu Y et al (2021) Pandemic-related financial market volatility spillovers: evidence from the Chinese COVID-19 epicentre. Int Rev Econ Financ 71:55-81. https://doi.org/10.1016/ j.iref.2020.06.022

Cuadro-Sáez L, García-Herrero A (2007) Finance for growth: does a balanced financial structure matter? Kiel Advanced Studies Working Papers 445, Kiel Institute for the World Economy (IfW)

Donoho DL, Johnstone IM (1995) Adapting to unknown smoothness via wavelet shrinkage. J Am Stat Assoc 90:1200-1224. https://doi.org/ $10.1080 / 01621459.1995 .10476626$

Esso LJ, Keho Y (2016) Energy consumption, economic growth and carbon emissions: cointegration and causality evidence from selected African countries. Energy 114:492-497

Geweke J (1992) Evaluating the accuracy of sampling-based approaches to the calculation of posterior moments. In: Bernardo JM, Berger JO, Dawid AP, Smith AFM (eds) Bayesian statistics, vol. 4. Clarendon Press, Oxford, pp 169-193

Gharib C, Mefteh-Wali S, Ben JS (2020) The bubble contagion effect of COVID-19 outbreak: evidence from crude oil and gold markets. Financ Res Lett 38:101703. https://doi.org/10.1016/j.frl.2020. 101703

Granger CWJ, Ramanathan R (1984) Improved methods of combining forecasts. J Forecast 3:197-204. https://doi.org/10.1002/for. 3980030207

Grinsted A, Moore JC, Jevrejeva S (2004) Application of the cross wavelet transform and wavelet coherence to geophysical time series. Nonlinear Process Geophys 11:561-566. https://doi.org/10.5194/ npg-11-561-2004

Haarmeyer D (2020) Private equity and the COVID-19 economic downturn: opportunity for expansion? J Appl Corp Financ 32:87-91. https://doi.org/10.1111/jacf.12420

He W, Abbas Q, Alharthi M, Mohsin M, Hanif I, Vinh Vo X, Taghizadeh-Hesary F (2020) Integration of renewable hydrogen in light-duty vehicle: nexus between energy security and low carbon emission resources. Int J Hydrog Energy 45:27958-27968. https:// doi.org/10.1016/j.ijhydene.2020.06.177

Ikram M, Mahmoudi A, Shah SZA, Mohsin M (2019a) Forecasting number of ISO 14001 certifications of selected countries: application of even GM (1,1), DGM, and NDGM models. Environ Sci Pollut Res. https://doi.org/10.1007/s11356-019-04534-2 
Ikram M, Sroufe R, Mohsin M, Solangi YA, Shah SZA, Shahzad F (2019b) Does CSR influence firm performance? A longitudinal study of SME sectors of Pakistan. J Glob Responsib 11:27-53. https://doi.org/10.1108/jgr-12-2018-0088

IMF (2020) Policy responses to COVID-19. https://www.imf.org/en/ Topics/imf-and-covid19/Policy-Responses-to-COVID-19

Iqbal W, Fatima A, Yumei H, Abbas Q, Iram R (2020) Oil supply risk and affecting parameters associated with oil supplementation and disruption. J Clean Prod 255. https://doi.org/10.1016/j.jclepro. 2020.120187

Iram R, Anser MK, Awan RU et al (2020) Prioritization of renewable solar energy to prevent energy insecurity: an integrated role. Singap Econ Rev 1-22. https://doi.org/10.1142/S021759082043002X

Jelilov G, Iorember PT, Usman O, Yua PM (2020) Testing the nexus between stock market returns and inflation in Nigeria: does the effect of COVID-19 pandemic matter? J Public Aff. https://doi.org/10. 1002/pa.2289

Kannan S, Shaik Syed Ali P, Sheeza A, Hemalatha K (2020) COVID-19 (novel coronavirus 2019) - recent trends. Eur Rev Med Pharmacol Sci. https://doi.org/10.26355/eurrev 20200220378

Khalid Anser M, Hina T, Hameed S et al (2020) Modeling adaptation strategies against climate change impacts in integrated rice-wheat agricultural production system of Pakistan. Int J Environ Res Public Health 17. https://doi.org/10.3390/ijerph17072522

Kisi O, Cimen M (2011) A wavelet-support vector machine conjunction model for monthly streamflow forecasting. J Hydrol 399:132-140. https://doi.org/10.1016/j.jhydrol.2010.12.041

Lopez-Tiro F, Peregrina-Barreto H, Rangel-Magdaleno J et al (2020) Effect of the exposure time in laser speckle imaging for improving blood vessels localization: a wavelet approach. In: I2MTC 2020 International Instrumentation and Measurement Technology Conference, Proceedings

Malhotra A, Chintanpalli A (2020) A real time wavelet filtering for ECG baseline wandering removal. In: 2020 International Conference on Artificial Intelligence and Signal Processing, AISP 2020

Mohsin M, Rasheed AK, Saidur R (2018a) Economic viability and production capacity of wind generated renewable hydrogen. Int $\mathrm{J}$ Hydrog Energy 43:2621-2630

Mohsin M, Zhou P, Iqbal N, Shah SAA (2018b) Assessing oil supply security of South Asia. Energy 155:438-447. https://doi.org/10. 1016/J.ENERGY.2018.04.116

Mohsin M, Rasheed AK, Sun H, Zhang J, Iram R, Iqbal N, Abbas Q (2019) Developing low carbon economies: an aggregated composite index based on carbon emissions. Sustain Energy Technol Assess 35:365-374. https://doi.org/10.1016/j.seta.2019.08.003

Mohsin M, Taghizadeh-Hesary F, Panthamit N, Anwar S, Abbas Q, Vo XV (2020) Developing low carbon finance index: evidence from developed and developing economies. Financ Res Lett 101520. https://doi.org/10.1016/j.frl.2020.101520

Mohsin M, Hanif I, Taghizadeh-Hesary F, Abbas Q, Iqbal W (2021) Nexus between energy efficiency and electricity reforms: a DEAbased way forward for clean power development. Energy Policy 149:112052. https://doi.org/10.1016/j.enpol.2020.112052

Mzoughi H, Urom C, Uddin GS, Guesmi K (2020) The effects of COVID-19 pandemic on oil prices, $\mathrm{CO} 2$ emissions and the stock market: evidence from a VAR Model. SSRN Electron J. https://doi. org $/ 10.2139 /$ ssrn.3587906

Personal M, Archive R, Roncalli T, Weisang G (2016) Do spot and future palm oil prices influence the stock market prices of a major palm oil producer? the Malaysian experience. Munich Pers RePEc Arch. https://doi.org/10.13140/RG.2.1.3253.7368
Prabheesh KP, Padhan R, Garg B (2020) COVID-19 and the oil price stock market nexus: evidence from net oil-importing countries. Energy Res Lett. https://doi.org/10.46557/001c.13745

Ren S, Yuan B, Ma X, Chen X (2014) International trade, FDI (foreign direct investment) and embodied $\mathrm{CO} 2$ emissions: a case study of Chinas industrial sectors. China Econ Rev 28:123-134

Samadi AH, Owjimehr S, Nezhad Halafi Z (2020) The cross-impact between financial markets, Covid-19 pandemic, and economic sanctions: The case of Iran. J Policy Model. https://doi.org/10.1016/j. jpolmod.2020.08.001

Sarker SA, Wang S, Mehedi Adnan KM et al (2020) Economic viability and socio-environmental impacts of solar home systems for off-grid rural electrification in Bangladesh. Energies 13. https://doi.org/10. 3390/en13030679

Sarkis J, Cohen MJ, Dewick P, Schröder P (2020) A brave new world: lessons from the COVID-19 pandemic for transitioning to sustainable supply and production. Resour Conserv Recycl 159:104894

Sudha G, Sornaganesh V, Thangajesu Sathish M (2020) Impact of indian stock market due to crisis in March 2020

Sun HP, Tariq G, Haris M, Mohsin M (2019) Evaluating the environmental effects of economic openness: evidence from SAARC countries. Environ Sci Pollut Res 26:24542-24551. https://doi.org/10. 1007/s11356-019-05750-6

Sun H, Pofoura AK, Adjei Mensah I, Li L, Mohsin M (2020a) The role of environmental entrepreneurship for sustainable development: evidence from 35 countries in Sub-Saharan Africa. Sci Total Environ 741:140132. https://doi.org/10.1016/j.scitotenv.2020.140132

Sun L, Cao X, Alharthi M, Zhang J, Taghizadeh-Hesary F, Mohsin M (2020b) Carbon emission transfer strategies in supply chain with lag time of emission reduction technologies and low-carbon preference of consumers. J Clean Prod 264:121664. https://doi.org/10.1016/j. jclepro.2020.121664

Sun L, Qin L, Taghizadeh-Hesary F, Zhang J, Mohsin M, Chaudhry IS (2020c) Analyzing carbon emission transfer network structure among provinces in China: new evidence from social network analysis. Environ Sci Pollut Res 27:23281-23300. https://doi.org/10. 1007/s11356-020-08911-0

Tehreem HS, Anser MK, Nassani AA, Abro MMQ, Zaman K (2020) Impact of average temperature, energy demand, sectoral value added, and population growth on water resource quality and mortality rate: it is time to stop waiting around. Environ Sci Pollut Res 27: 37626-37644. https://doi.org/10.1007/s11356-020-09822-w

Tiep NC, Wang M, Mohsin M, Kamran HW, Yazdi FA (2021) An assessment of power sector reforms and utility performance to strengthen consumer self-confidence towards private investment. Econ Anal Policy 69:676-689. https://doi.org/10.1016/j.eap.2021. 01.005

Toda HY, Yamamoto T (1995) Statistical inference in vector autoregressions with possibly integrated processes. J Econ 66: 225-250. https://doi.org/10.1016/0304-4076(94)01616-8

Torrence C, Compo GP (1998) A practical guide to wavelet analysis. Bull Am Meteorol Soc 79:61-78. https://doi.org/10.1175/15200477(1998)079<0061:APGTWA>2.0.CO;2

Wasif Rasheed HM, Anser MK (2017) Effect on brand loyalty in mobile phone purchasing (a case study in Bahawalpur, Pakistan). J Public Adm Gov 7. https://doi.org/10.5296/jpag.v7i1.11042

World Bank Group (2018) World Bank. http://documents.worldbank. org/curated/en/630671538158537244/The-World-Bank-AnnualReport-2018

World Health Organization (2020) https://covid19.who.int/?gclid= CjwKCAiAg8OBBhA8EiwA1Kw3kv_-zJa6AtkQVB_ 
$8 \mathrm{Zn} \mathrm{Th} \mathrm{B} \mathrm{d} \mathrm{M} \mathrm{c} \mathrm{s} \mathrm{v} \mathrm{C} 1$ i P O V g 8 knsRZvobumF23FbaCNRoC4PAQAvD_BwE

Xu Y, Chen Z, Peng MYP, Anser MK (2020) Enhancing consumer online purchase intention through gamification in China: perspective of cognitive evaluation theory. Front Psychol 11. https://doi.org/ 10.3389/fpsyg. 2020.581200

Yang Z, Abbas Q, Hanif I, Alharthi M, Taghizadeh-Hesary F, Aziz B, Mohsin M (2021) Short- and long-run influence of energy utilization and economic growth on carbon discharge in emerging SREB economies. Renew Energy 165:43-51. https://doi.org/10.1016/j. renene.2020.10.141

Yousaf S, Anser MK, Tariq M, Sahibzada Jawad SUR, Naushad S, Yousaf Z (2020) Does technology orientation predict firm performance through firm innovativeness? World J Entrep Manag Sustain Dev 17:140-151. https://doi.org/10.1108/WJEMSD-11-2019-0091

Publisher's note Springer Nature remains neutral with regard to jurisdictional claims in published maps and institutional affiliations. 